\title{
REFLEXÃO ACERCA DOS EFEITOS DA RESPONSABILIDADE TRIBUTÁRIA TAL COMO PROPOSTA NO CÓDIGO TRIBUTÁRIO NACIONAL
}

REFLECTION ON THE EFFECTS OF TAX LIABILITY AS PROPOSED IN THE NATIONAL TAX CODE

REFLEXIÓN ACERCA DE LOS EFECTOS DE LA RESPONSABILIDAD TRIBUTARIA TAL COMO ESTÁ PROPUESTA EN EL CÓDIGO TRIBUTARIO NACIONAL

Ubaldo Cesar Balthazar ${ }^{1}$

Vicente Lisboa Capella²

1 Professor de Direito Tributário da Universidade Federal de Santa Catarina (UFSC). Doutor em Direito pela Universidade Livre de Bruxelas, Bélgica. Advogado.

2 Professor de Direito Tributário da Universidade do Sul de Santa Catarina (Unisul). Mestre em Direito pela UFSC. Advogado. 
Resumo: O presente artigo pretende realizar uma reflexão acerca do fenômeno dos efeitos da responsabilidade tributária, conforme disposto no Código Tributário Nacional. Neste sentido, embora faça uma rápida referência à noção de sujeito ativo da obrigação, vai debruçar-se com mais atenção na figura do sujeito passivo, em seu desdobramento, previsto no CTN, em contribuinte e responsável. Neste aspecto, aborda-se $\mathrm{o}$ instituto da responsabilidade tributária, com referência às classificações doutrinárias que pretendem caracterizá-la, bem como às modalidades previstas no CTN. Conclui-se, após tais considerações, que a responsabilidade tributária tem como efeito a solidariedade - entre o terceiro e o contribuinte, a subsidiariedade do responsável - quando não seja possível cobrar a dívida do contribuinte, ou a liberação deste - com a consequente cobrança do crédito exclusiva e pessoalmente do terceiro responsável. Pretende-se, com essa análise, elucidar alguns aspectos do fenômeno da sujeição passiva indireta, que tantas controvérsias provoca na doutrina brasileira.

Palavras-chave: Tributos. Sujeito passivo. Responsabilidade tributária. Solidariedade. Subsidiariedade.

Abstract: This article reflects on the phenomenon of the effects of tax liability, as determined by the National Tax Code (NTC). In this sense, although it makes a brief reference to the notion of the obligation of the active subject, it focuses more closely on the figure of the taxable person, in its unfolding, as provided for in the NTC, as contributor and responsible party. In this aspect, it addresses the institute of tax liability with reference to the doctrinal ratings that are intended to characterize it, as well as the terms provided by the NTC. It is concluded, after this consideration, that tax liability has a solidarity effect -between the third party and the taxpayer, the subsidiarity of the responsible party - when it is not possible to collect the debt from the taxpayer, or to release it - with the consequent recovery of the credit solely and exclusively from the responsible third party. Through this analysis, this article elucidates some aspects of the phenomenon of indirect passive subjection, which has led to many controversies in the Brazilian doctrine. 
Keywords: Taxes. Taxpayer. Tax responsibility. Solidarity. Subsidiarity.

Resumen: El presente artículo intenta realizar una reflexión acerca del fenómeno de los efectos de la responsabilidad tributaria conforme está dispuesto en el Código Tributario Nacional. En este sentido, aunque haga una rápida referencia a la noción de sujeto activo de la obligación, va a dedicarse con más atención a la figura del sujeto pasivo, en su desdoblamiento previsto en el CTN como contribuyente y responsable. En este aspecto, se aborda el instituto de la responsabilidad tributaria con referencia a las clasificaciones doctrinarias que pretenden caracterizarla, así como a las modalidades previstas en el CTN. Tras tales consideraciones, se concluye que la responsabilidad tributaria tiene como efecto la solidaridad - entre el tercero y el contribuyente, la subsidiariedad del responsable - cuando no es posible cobrar la deuda del contribuyente, o la liberación del mismo - con la consecuente cobranza del crédito exclusiva y personalmente del tercero responsable. Con este análisis se quieren dilucidar algunos aspectos del fenómeno de la sujeción pasiva indirecta, que tantas controversias provoca en la doctrina brasileña.

Palabras clave: Tributos. Sujeto pasivo. Responsabilidad tributaria. Solidaridad. Subsidiariedad.

\section{INTRODUÇÃO}

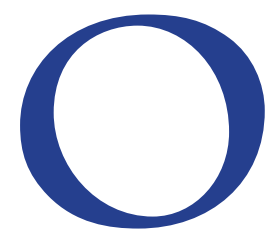

$s$ tributos têm como principal finalidade o financiamento das atividades do Estado. Esta é noção cediça, de um lado a população demanda mais serviços públicos, mas repudia a carga tributária que suporta. Em outra ponta o Poder Público busca atender às demandas da sociedade e, para tanto, aumenta a tributação. É no contexto dessa disputa constante que está situado o Direito Tributário, impondo limites a ambos 3 .

3 "Vivemos até a Constituição de 88 uma estrutura tributária em que o grande personagem era o Estado com sua autoridade; neste contexto, cobrava-se tributo porque o Estado 'podia', estava investido de um poder jurisdicionado e o exercia. Diante dela, o máximo que a sociedade civil podia fazer era encontrar limites, impor restrições, proibições, e os grandes 
A relação jurídico-tributária corresponde à possibilidade do Fisco exigir de alguém determinada prestação, pecuniária ou não, em virtude da ocorrência de determinado fato jurídico, conforme ensina Paulo de Barros Carvalho ${ }^{4}$. O objeto da prestação, denominado no direito positivo como "obrigação tributária", tanto pode referir-se a um dever de cunho patrimonial como não patrimonial. No primeiro caso o $\mathrm{CTN}^{5}$ utiliza a denominação obrigação principal e, nos demais, obrigação acessória ou, como preferem alguns autores ${ }^{6}$, dever instrumental.

A vinculação das partes depende da existência de prévia determinação/ descrição legal (hipótese de incidência ${ }^{7}$ ), mas não nasce diretamente da lei. Somente ao acontecer no mundo fático a previsão legal (ocorrência do fato gerador $^{8}$ ) é que ensejará a relação entre os sujeitos. Ocorrido o fato gerador nasce um liame jurídico que une os envolvidos, tendo como elo a obrigação prevista na norma legal. Ou seja, ocorrido o fato A (antecedente), é devida uma prestação $B$ (consequente) que liga as partes dessa relação, denominadas sujeitos ativo e passivo.

princípios tributários discutidos na vigência da Constituição de 67 começavam todos com um 'não': 'não pode cobrar tributos sem lei; não pode cobrar para o passado; não pode confiscar' etc. Sempre uma ideia de bloqueio, de restrição, de impedimento à ação do Estado. A grande novidade trazida pela Constituição Federal de 1988 foi colocar a tributação como instrumento para a sociedade civil alcançar seus objetivos e posicionar o próprio Estado como criatura perante a sociedade civil. Neste contexto, o Estado não está mais investido de um poder puro; está investido de uma função a exercer perante a sociedade civil. Quem tem função deve prestar contas, precisa justificar seus atos, necessita encontrar sua posição relativa dentro do contexto e não pura e simplesmente se investir de determinada prerrogativa e dizer 'cobro porque posso (= tenho competência, logo tenho poder)." (GRECO, Marco Aurélio. Responsabilidade de terceiros e crédito tributário: três temas atuais. Revista Fórum de Direito Tributário - RFDT, Belo Horizonte, n. 28, p. 235-249, jul./ago. 2007. p. 240).

4 CARVALHO, Paulo de Barros. Curso de direito tributário. 14. ed. rev. e atual. São Paulo: Saraiva, 2002. p. 279.

$5 \quad$ Vide art. 113 do CTN.

6 CARVALHO, Paulo de Barros. Curso de direito tributário. 14. ed. rev. e atual. São Paulo: Saraiva, 2002. p. 284-297.

7 A utilização por parte do CTN da mesma expressão, "fato gerador", para tratar da norma legal e da correspondente situação fática no mundo real sofre várias críticas por parte da doutrina. Para manter o rigor científico e evitar confusões, sem perder o foco, adota-se nesta reflexão a expressão "hipótese de incidência" para tratar da previsão geral e abstrata contida na lei, conforme Alfredo Augusto Becker (BECKER, Alfredo Augusto. Teoria geral do direito tributário. 2. ed. São Paulo: Saraiva, 1972. p. 30).

8 Pelas razões expostas na nota anterior e em virtude das colocações de Luciano Amaro, utiliza-se a expressão "fato gerador" empregada no CTN quando se estiver referindo ao fato concreto ocorrido no mundo real nos moldes previstos previamente na norma legal (hipótese de incidência) (vide AMARO, Luciano. Direito tributário brasileiro. 14. ed. São Paulo: Saraiva, 2008. p. 257-262). 
O sujeito ativo da obrigação tributária é a pessoa de direito público ou privado ${ }^{9}$ que possui capacidade para exigir a referida prestação pela fiscalização e arrecadação. Apesar do art. 119 do CTN"10 fazer referência à "competência", a expressão é objeto de críticas ${ }^{11}$ em virtude de se tratar da possibilidade de legislar sobre a matéria tributária e não de compelir o atendimento do objeto da obrigação. No polo oposto da relação jurídico-tributária está o sujeito passivo, conforme abordado no item seguinte.

\section{O SUJEITO PASSIVO DA OBRIGAÇÃO PRINCIPAL}

O polo passivo da relação tributária é ocupado por uma pessoa que, em virtude da existência de previsão legal anterior e da ocorrência da correspondente situação no mundo fenomênico, deve prestar o objeto da obrigação. Essa pessoa pode ser física ou jurídica, de direito público ou privado. Seguindo Regina Helena Costa, o sujeito passivo da obrigação tributária "é aquele a quem incumbe o cumprimento da prestação de natureza fiscal, seja o pagamento de tributo, seja um comportamento positivo ou negativo, estatuído no interesse da arrecadação tributária"12 ou contra quem foi imposta penalidade.

Nos moldes previstos no art. 121 do CTN, toda pessoa obrigada ao pagamento de tributo ou penalidade pecuniária é o sujeito passivo da obrigação principal. De fato, está-se diante do devedor da relação tributária que tem para com a parte contrária, sujeito ativo, o dever de pagar o tributo ou multa, como resume Amílcar Falcão13.

Assim sendo, todo aquele que se vir investido, por força da lei, na obrigação de pagar um tributo, automaticamente adquire o status de

9 Conf. CARVALHO, Paulo de Barros. Curso de direito tributário. 14. ed. rev. e atual. - São Paulo: Saraiva, 2002. p. 293-296; TAVARES, Alexandre Macedo. Fundamentos de direito tributário. 4. ed. São Paulo: Saraiva, 2009. p. 126-128; COSTA, Regina Helena. Curso de direito tributário: Constituição e Código tributário nacional. São Paulo: Saraiva, 2009. p. 188-189.

10 "Art. 119. Sujeito ativo da obrigação é a pessoa jurídica de direito público, titular da competência para exigir o seu cumprimento."

11 Vide DIFINI. Luiz Felipe Silveira. Manual de direito tributário. 4. ed. atual. São Paulo: Saraiva, 2008. p. 210-212.

12 COSTA, Regina Helena. Curso de direito tributário: Constituição e código tributário nacional. São Paulo: Saraiva, 2009. p. 190.

13 FALCÃO, Amílcar. Introdução ao direito tributário. 5. ed. atual. rev. atualizada por Flávio Bauer Novelli. Rio de Janeiro: Forense, 1994. p. 86. 
sujeito passivo tributário e, como tal, Ihe incumbirão todos os deveres e lhes serão concedidos todos os direitos inerentes à relação tributária. [...] Inegavelmente, por uma decorrência mesmo do seu status, é-lhe dado impugnar (modo de apuração do quantum no processo de lançamento etc.), quer quanto à sua constitucionalidade (previsão em lei, autorização orçamentária, competência impositiva do poder tributante e demais restrições constitucionais).

Os sujeitos passivos podem ser divididos, tomando-se como critério a relação do sujeito com o fato gerador, em contribuinte e responsável. O primeiro quando ele mesmo realiza o fato jurídico previsto na norma (fato gerador) e passa a ser obrigado pela prestação. Responsável, quando, sem realizar o fato gerador, torna-se devedor em virtude de uma previsão legal aplicável a ele.

Em um momento pré-jurídico ${ }^{14}$ a definição do contribuinte passa pela identificação da materialidade da hipótese de incidência que corresponderá a uma riqueza a ser tributada ${ }^{15}$. Idealmente a escolha do fato que, se ocorrido no mundo real, dará ensejo à obrigação tributária principal e deve atender ao princípio da capacidade contributiva. Ou, nas palavras de Alfredo Augusto Becker ${ }^{16}$, deve ser possível verificar a existência de fatos - signo - presuntivos de riqueza. Essa eleição foi feita em grande parte pela Constituição ao definir o imposto de importação, imposto sobre propriedade territorial rural, imposto sobre produtos industrializados, entre outros. Nos tributos não vinculados, os contribuintes são as pessoas que realizam tais atos ou enquadrem-se nas situações previstas como importador, proprietário da área rural ou industrial. ${ }^{17}$

No caso dos tributos vinculados, o contribuinte é aquele a quem a atividade estatal é direcionada. Ou seja, nas taxas e na contribuição de melhoria quem realiza o fato gerador é o próprio Estado. O contribuinte é aquele que recebe o serviço público específico e divisível, sofre o exercício do poder de polícia ou tem seu imóvel valorizado em decorrência de uma obra pública.

14 ATALIBA, Geraldo. Hipótese de incidência tributária. 4. ed. São Paulo: Malheiros, 2003. p. 86-88.

15 Conf. BECHO, Renato Lopes. Sujeição passiva e responsabilidade tributária. São Paulo: Dialética, 2000. p. 78.

16 BECKER, Alfredo Augusto. Teoria geral do direito tributário. 2. ed. São Paulo: Saraiva, 1972. p. 458-462.

17 Conf. BECHO, Renato Lopes. Sujeição passiva e responsabilidade tributária. São Paulo: Dialética, 2000. p. 78. 
Nesse sentido, para Mauro Luís Rocha Lopes não seria necessário que a lei tributária fizesse indicação expressa do contribuinte, vez que "constando da lei, necessariamente, a situação substancial sobre a qual recai a exação, a figura do contribuinte acaba sendo concebida por inferência lógica." ${ }^{18}$ Posição essa inaugurada por Amílcar Falcão. ${ }^{19}$ No entanto, há situações previstas como núcleos materiais da hipótese de incidência que envolvem mais de uma pessoa, como nos casos de atos jurídicos, e qualquer uma delas poderá ser eleita como contribuinte. ${ }^{20}$

Feitas essas considerações, resta compreensível a escolha feita pelo CTN ${ }^{21}$ ao definir que é contribuinte aquele que possui relação pessoal e direta com a hipótese de incidência. O vocábulo direta guarda relação com a proximidade do contribuinte com o evento eleito no critério material para ensejar o nascimento da obrigação tributária.

Ao falar em relação pessoal, o que se pretendeu foi sublinhar a presença do contribuinte na situação que constitui o fato gerador. Ele deve participar pessoalmente do acontecimento fático que realiza o fato gerador. É claro que essa presença é jurídica e não necessariamente física (ou seja, o contribuinte pode relacionar-se com o fato gerador por intermédio de representante legal; o representante o faz presente). Ademais, quer o Código que essa relação seja direta. Em linguagem figurada, podemos dizer que o contribuintehá de serpersonagem de relevo no acontecimento, o personagem principal, e não mero coadjuvante. Ele deve ser identificado na pessoa em torno da qual giram os fatos. Se o fato gerador do imposto de renda, por exemplo, é a aquisição de renda, terá relação direta com esse fato a pessoa que aufere renda. Em certas situações (recorde-se o exemplo da transmissão de imóveis), a lei poderá ter de decidir entre duas pessoas que se apresentem em cena com igual destaque (no exemplo, o alienante e o adquirente). ${ }^{22}$

Renato Lopes Becho ${ }^{23}$ discorda de Luciano Amaro no exemplo final que trata do imposto de transmissão de bens imóveis entre vivos. Para o primeiro, aquele que

18 LOPES, Mauro Luís Rocha. Direito tributário brasileiro. 2. ed. Niterói, RJ: Impetus, 2010. p. 184.

19 FALCÃO, Amílcar. Introdução ao direito tributário. 5. ed. atual. rev. atualizada por Flávio Bauer Novelli. Rio de Janeiro: Forense, 1994. p. 87.

20 Vide arts. 42 e 66 do CTN.

21 Vide art. 121, I, do CTN.

22 AMARO, Luciano. Direito tributário brasileiro. 14. ed. São Paulo: Saraiva, 2008. p. 297.

23 BECHO, Renato Lopes. As modalidades de sujeição passiva tributária no ordenamento jurídico brasileiro. Revista Dialética de direito tributário - RDDT, São Paulo, n. 192, p. 113-131, set. 2011. p. 125. 
realiza o ato de transmitir é o vendedor, mesmo sendo necessária a existência de outra parte. O comprador não transmite o bem, apenas o recebe, não podendo, segundo o autor, ser considerado contribuinte.

Assim, quando o próprio sujeito passivo eleito pela norma realizar ou enquadrarse no fato gerador será denominado contribuinte. Como regra, originariamente ${ }^{24}$ a dívida recai sobre o contribuinte, sendo este o titular do débito. ${ }^{25} \mathrm{Ou}$, em outras palavras, seria o contribuinte o devedor por excelência.

\section{RESPONSABILIDADE TRIBUTÁRIA}

Antes de adentrar na análise do responsável tributário, é necessário tecer algumas considerações sobre a abrangência do vocábulo responsável, que pode ter vários sentidos diferentes. Utilizado de maneira genérica ${ }^{26}$, como faz o CTN no art. 123, equivale ao dever de cumprir uma obrigação: o contribuinte é responsável por pagar o tributo. Assim, no sentido lato, tanto contribuintes como responsáveis respondem por uma obrigação tributária. No entanto, para manter o rigor científico necessário e evitar confusões, utiliza-se o termo para tratar o sujeito passivo abordado a seguir.

O responsável tributário é uma terceira pessoa distinta do contribuinte que, apesar de não realizar o fato gerador, pode ser chamada ao pagamento em virtude de previsão legal. Assim, sujeito passivo é gênero do qual são espécies o contribuinte e o responsável. Parte da doutrina ${ }^{27}$ utiliza a expressão sujeito passivo direto para referir-se ao devedor originariamente fixado por lei e sujeito passivo indireto para tratar do terceiro que possa fazer parte do polo passivo. "O contribuinte tem o dever jurídico e tem, também a responsabilidade [lato], salvo dispositivo expresso de lei que a exclua. Já o responsável não tem dever jurídico, 24 FALCÃO, Amílcar. Introdução ao direito tributário. 5. ed. atual. rev. atualizada por Flávio Bauer Novelli. Rio de Janeiro: Forense, 1994. p. 87.

25 FERREIRA, Richard Edward Dooli T. A sujeição passiva tributária e a retenção de tributos na fonte. Rio de Janeiro: Lumen Juris, 2008. p. 55.

26 Ver também o art. 128 do CTN que faz referência "a responsabilidade do contribuinte".

27 SOUZA, Rubens Gomes de. Compêndio de legislação tributária. Rio de Janeiro: Edições Financeiras S.A., 1952. p. 65-67; AMARO, Luciano. Direito tributário brasileiro. 14. ed. São Paulo: Saraiva, 2008. p. 303-305; TAVARES, Alexandre Macedo. Fundamentos de direito tributário. 4. ed. São Paulo: Saraiva, 2009. p. 129. 
mas tem a responsabilidade tributária." 28

A previsão contida no CTN para possibilitar terceiro a pagar o tributo que, em princípio, seria devido pelo contribuinte, justifica-se pela comodidade ${ }^{29}$ e praticidade ${ }^{30}$ na arrecadação, atribuindo ao sujeito ativo uma garantia extra. ${ }^{31}$ Nas palavras de Rubens Gomes de Souza, seria utilizada quando "o Estado tenha interesse ou necessidade de cobrar o tributo de pessoa diferente" 32 do contribuinte. Claudio Carneiro ${ }^{33}$ ainda acrescenta o impedimento de fraudes com uma de suas finalidades.

A redação isolada do art. 121, inciso II, do CTN incita dúvida quanto à suficiência de determinação legal para obrigar terceira pessoa ao pagamento dos créditos tributários. Em outras palavras, é questionável a possibilidade da lei prever indiscriminadamente a responsabilidade tributária. O próprio CTN em seu art. 128 estabelece a necessidade da existência de um vínculo do terceiro com o fato gerador realizado pelo contribuinte. Assim, para a existência da responsabilidade tributária, nos termos do CTN, em princípio, são necessárias: (i) a disposição legal expressa, (ii) a terceira pessoa, e (iii) a vinculação indireta dessa com o fato gerador.

A proximidade dos sujeitos passivos com o fato gerador seria o elo que define e separa o contribuinte e o responsável. De fato, em ambas as situações é indispensável a tipificação legal ${ }^{34}$, restando o critério da força da ligação com

28 MACHADO. Hugo de Brito Machado. A solidariedade na relação tributária e a liberdade do legislador no art. 124, II, do CTN. Revista Dialética de direito tributário - RDDT, São Paulo, n. 195, p. 58-67, dez. 2011.

29 BALEEIRO, Aliomar. Direito tributário brasileiro. 11. ed. atualizada por Misabel Abreu Machado Derzi. Rio de Janeiro: Forense, 1999. p. 735.

30 FERREIRA, Richard Edward Dooli T. A sujeição passiva tributária e a retenção de tributos na fonte. Rio de Janeiro: Lumen Juris, 2008. p. 91-97; TIPKE, Klaus; YAMASHITA, Douglas. Justiça fiscal e princípio da capacidade contributiva. São Paulo: Malheiros, 2002. p. 38-39.

31 "Assume relevância a preocupação com o credor e o crédito, viés que está também retratado na legislação tributária. Basta ver o que aconteceu nos últimos dez anos: cautelar fiscal, arrolamento fiscal, penhora on-line, CADIN, bloqueio de CPF, certidões para levantar valores depositados em juízo, mudança da definição de fraude à execução etc. O foco não é mais o devedor e sua dívida; passou a ser o credor e seu crédito." (GRECO, Marco Aurélio. Responsabilidade de terceiros e crédito tributário: três temas atuais. Revista Fórum de Direito Tributário - RFDT, Belo Horizonte, n. 28, p. 235-249, jul./ago. 2007. p. 242).

32 SOUZA, Rubens Gomes de. Compêndio de legislação tributária. Rio de Janeiro: Edições Financeiras S.A., 1952. p. 66.

33 CARNEIRO, Claudio. Curso de direito tributário e financeiro: obra já atualizada com a LC 128/08 e as MPs 449/08 e 451/08. Rio de Janeiro: Lumen Juris, 2009. p. 246.

34 Vide art. 97, III, do CTN. 
o fato gerador para estabelecer os papéis na relação jurídica. Além disso, o CTN, ao definir o responsável, o faz por exclusão ao afirmar que é outra pessoa que não o contribuinte. Sendo contribuinte, não será responsável, nos termos do art. 128, II, do CTN.

Maria Rita Ferragut entende ser possível eleger os responsáveis entre aqueles "(i) indiretamente vinculados ao fato jurídico tributário ou (ii) direta ou indiretamente vinculadas ao sujeito que o praticou." 35 Apesar da própria autora reconhecer que essa visão alarga o conceito previsto no art. 128 do CTN, defende esse ponto de vista confrontando as previsões do CTN em que não é possível identificar a relação indireta do responsável com o fato gerador. Para justificar sua posição, exemplifica com a responsabilidade da sociedade incorporadora pelos tributos devidos pela incorporada.

Para tentar conciliar a redação do CTN com a eleição dos responsáveis feita por Maria Rita Ferragut, deve-se interpretar a expressão "fato gerador" utilizada no art. 128 do CTN. O dispositivo exige que o responsável esteja "vinculado ao fato gerador da respectiva obrigação" realizado pelo contribuinte. Indiscutivelmente, não basta para o nascimento da obrigação tributária a ocorrência no mundo real apenas do critério material previsto na lei. Se assim fosse, o proprietário de terras rurais na Argentina seria devedor do ITR no Brasil. É necessário atendimento dos demais elementos previstos para que a norma gere seus efeitos, fazendo nascer a relação jurídica entre o contribuinte e o fisco.

Assim, deve-se interpretar o vínculo do terceiro com o "fato gerador" como a necessidade de relação do responsável com os critérios necessários ao surgimento da obrigação. Geraldo Ataliba ${ }^{36}$ indica a existência de cinco elementos essenciais: material, pessoal, quantitativo, temporal e espacial. Podese afirmar que, para Maria Rita Ferragut, seria necessária a relação do terceiro apenas com o critério material ou pessoal para possibilitar a instituição da responsabilidade do terceiro.

35 FERRAGUT, Maria Rita. Responsabilidade tributária e o código civil de 2002. São Paulo: Noeses, 2009. p. 38.

36 Conf. ATALIBA, Geraldo. Hipótese de incidência tributária. 4. ed. São Paulo: Malheiros, 2003. p. 102-116. 
Apesar do CTN mencionar a relação indireta do responsável com o fato gerador, entendendo-se nesse primeiro momento como o núcleo material, o próprio código relaciona várias hipóteses em que tal relação não pode ser percebida. Assim, deve-se entender de forma extensiva a referência feita ao "fato gerador" pelo art. 128 para incluir-se como alternativa a vinculação entre o contribuinte e o terceiro (elemento pessoal).

Por outra via, Marcus Vinicius Neder ${ }^{37}$ justifica a contradição entre o art. 128 e as demais previsões do CTN, em que não se verifica a relação indireta do responsável com o fato gerador na ressalva do dispositivo mencionado. Acredita que a indicação inicial do caput ("Sem prejuízo do disposto neste capítulo") demonstraria que existam exceções à regra no próprio CTN. De forma semelhante, Paulo de Barros Carvalho ${ }^{38}$ defende que existe um rumo interno à situação tributável da responsabilização e outro externo. O primeiro estaria, nos termos do art. 128 do CTN, ligado indiretamente ao fato gerador, enquanto o segundo, previsto na ressalva inicial do mesmo dispositivo, estaria previsto nas demais regras do CTN (arts. 129 até 138).

Para os dois autores mencionados, o conceito de responsabilidade trazido no CTN, que prevê a necessidade do vínculo do terceiro com o fato gerador, não seria taxativo, pois não prevê a possibilidade de responsabilização no caso de ligação do terceiro com o contribuinte, fazendo referência apenas às ligações do primeiro com o fato gerador realizado pelo contribuinte. Levando-se adiante esse pensamento, poderia a lei instituir hipótese de responsabilidade independente da existência de qualquer relação entre o responsável e o fato gerador realizado pelo contribuinte, o que parece possibilitar a exigência de créditos de terceiros totalmente alheios à relação jurídica sem qualquer limite.

Outro elemento parece fornecer os parâmetros para a delimitação do responsável. Alexandre Macedo Tavares defende que deve haver a possibilidade de o terceiro ter meios para compelir o contribuinte, devedor originário, a pagar 37 NEDER, Marcos Vinicius. Solidariedade de direito e de fato: reflexões acerca de seu conceito. In: Responsabilidade tributária. FERRAGUT, Maria Rita (Coord.). São Paulo: Dialética, 2007. p. 27-47.

38 CARVALHO, Paulo de Barros. Curso de direito tributário. 14. ed. rev. e atual. São Paulo: Saraiva, 2002. p. 314-315. 
o valor devido com recursos próprios. ${ }^{39} \mathrm{Na}$ mesma linha, Luciano Amaro salienta ser "necessário que a natureza do vínculo permita a esse terceiro, elegível como responsável, fazer com que o tributo seja recolhido sem onerar seu próprio bolso." Isto é, o responsável deve ter meios de se precaver de suportar o débito com seu próprio patrimônio.

Assim, não bastariam os elementos indicados anteriormente, mas também a possibilidade da outra pessoa "diligenciar no sentido de que o tributo seja recolhido à conta do indivíduo que, dado o fato gerador, seria elegível como contribuinte."40 Apesar desse requisito não constar expressamente no CTN, sua aplicação impede que o legislador eleja terceiro aleatoriamente, apenas para ver satisfeito seu crédito. Luís Eduardo Schoueri destaca que aceitar a indicação de outra pessoa sem qualquer possibilidade desta se ver ressarcida ou de efetuar a retenção do contribuinte seria equivalente a exigir um tributo de quem não realizou o fato gerador eleito na Constituição. Defende ainda que, sendo o débito originariamente devido por outra pessoa, "não há como justificar sua responsabilidade, senão pela possibilidade de ressarcimento ou retenção do contribuinte". ${ }^{41}$ Outra possibilidade de prevenir eventual responsabilização seria a atuação regular do terceiro dentro dos limites legais, do contrato social, estatutos ou mandato.

No entanto, o próprio CTN prevê a situação em que o responsável não possui qualquer forma de atuação que Ihe permita afastar a responsabilidade. O herdeiro será responsabilizado pelos débitos do contribuinte falecido, independente de sua atuação. Apesar de parecer contraditório com o exposto anteriormente, o dispositivo legal instituiu uma limitação que impede que o terceiro suporte com seu patrimônio o débito do de cujus. O CTN, em seu art. 131, ressaltou que o patrimônio pessoal do herdeiro não será afetado pelas dívidas do contribuinte falecido, limitando a responsabilidade ao montante do quinhão do legado. Nessa sistemática, os herdeiros

39 "Cumpre destacar, todavia, que o legislador, a seu bel-prazer, não pode eleger arbitrariamente qualquer pessoa como 'responsável' tributário por substituição, solidariedade ou subsidiariedade, ainda que conectada à hipótese de incidência, se por acaso essa mesma pessoa eleita não tiver como diligenciar no sentido de que o tributo seja pago à conta do indivíduo que, dada sua relação pessoal e direta com a situação que constitui a respectiva hipótese de incidência tributária, seria elegível como contribuinte." (TAVARES, Alexandre Macedo. Fundamentos de direito tributário. 4. ed. São Paulo: Saraiva, 2009. p. 130).

40 AMARO, Luciano. Direito tributário brasileiro. 14. ed. São Paulo: Saraiva, 2008. p. 312313.

41 SCHOUERI, Luís Eduardo. Direito tributário. São Paulo: Saraiva, 2011. p. 479-481. 
não correm qualquer risco de ter que arcar com os débitos do contribuinte com seu patrimônio próprio. Confirmando a necessidade de o terceiro dispor de meios para impedir que seu patrimônio seja atingido, o código estabelece que os bens do responsável não serão atingidos quando ele estiver impossibilitado de ver-se ressarcidos pelo contribuinte ou sua atuação for irrelevante.

Feitas as considerações anteriores, não se pode incorporar o conceito legal cegamente por possuir lacunas em face das previsões do próprio CTN. Assim, adota-se como conceito de responsável: (i) terceira pessoa que, sem se enquadrar na condição de contribuinte, pode ser incluída no polo passivo da relação tributária, (ii) mediante expressa previsão legal, (iii) em virtude de relacionar-se com o contribuinte ou indiretamente com o fato gerador e (iv) com meios de obrigar o contribuinte a suportar o encargo financeiro representado pelo tributo.

Definido quem pode ser responsável tributário, torna-se pertinente analisar as consequências da inclusão desse terceiro no polo passivo da relação tributária.

\section{CONSEQUÊNCIAS DA RESPONSABILIDADE TRIBUTÁRIA}

A fixação da responsabilidade tributária, além de outros elementos, depende, portanto, de previsão legal expressa. ${ }^{42}$ Quando caracterizada a responsabilidade, seu resultado será também definido por lei. O art. 128 do CTN, ao possibilitar a inclusão de terceira pessoa no polo passivo, prevê as consequências possíveis: (I) a atribuição de "responsabilidade supletiva"; e (II) com a exclusão do dever do contribuinte. Dois pontos devem ser destacados: a possibilidade de subdividir a primeira em solidariedade a subsidiariedade; e a ausência de autorização legal para a cobrança inicialmente do responsável e, na impossibilidade de fazê-lo, a exigência do contribuinte.

José Juan Ferreiro Lapatza43, ao abordar o tema da responsabilidade, destaca que são apenas duas as possibilidade da relação contribuinte e responsável na Espanha: "solidariedade ou subsidiariedade". Sem fazer qualquer menção à 42 Vide inciso III do art. 97 do CTN.

43 LAPATZA, José Juan Ferreiro. Direito tributário: teoria geral do tributo. Barueri, SP: Manole; Espanha, ES: Marcial Pons, 2007. p. 294. 
possibilidade de responsabilidade exclusiva do terceiro ${ }^{44}$.

Em contrapartida, no Brasil são três as possibilidades. O presente item tem a finalidade de analisar a responsabilidade tributária, tendo como ponto distintivo as implicações possíveis de sua existência45: (I.a) impor ao terceiro o pagamento solidário juntamente com o contribuinte; (I.b) estabelecimento de dever na impossibilidade de exigência do contribuinte; (II) liberação do contribuinte e atribuição do dever exclusivamente ao responsável. Renato Lopes Becho ${ }^{46}$ utiliza a expressão "possibilidade de efeitos diante da multiplicidade de sujeitos passivos" para referir-se à solidariedade, à subsidiariedade e à pessoalidade. Essa classificação será detalhada nos itens seguintes.

Não se ignora a existência de classificações que tomam outros critérios para categorizar a responsabilidade tributária. Rubens Gomes de Souza, Luciano Amaro e Alexandre Macedo Tavares ${ }^{47}$ utilizam o momento da caracterização da responsabilidade tributária para estudar esse fenômeno: responsabilidade por transferência e por substituição. No entanto, a classificação não pode ser mera exposição didática, mas deve servir para a análise do objeto do estudo. ${ }^{48}$ No 44 É pertinente acrescentar que o autor classifica os sujeitos passivos tributários em contribuintes, retentores e responsáveis. (LAPATZA, José Juan Ferreiro. Direito tributário: teoria geral do tributo. Barueri, SP: Manole; Espanha, ES: Marcial Pons, 2007. p. 294).

45 AGUILERA, Maria Lúcia. A responsabilidade de terceiros decorrente da prática de ilícitos e o lançamento de ofício: o caso da responsabilidade pessoal dos administradores. In: FERRAGUT, Maria Rita (Coord.) Responsabilidade tributária. São Paulo: Dialética, 2007. p. 140.

46 BECHO, Renato Lopes. As modalidades de sujeição passiva tributária no ordenamento jurídico brasileiro. Revista Dialética de direito tributário - RDDT, São Paulo, n. 192, p. 113-131, set. 2011. p. 127.

47 SOUZA, Rubens Gomes de. Compêndio de legislação tributária. Rio de Janeiro: Edições Financeiras S.A., 1952. p. 65-67; AMARO, Luciano. Direito tributário brasileiro. 14. ed. São Paulo: Saraiva, 2008. p. 303-305; TAVARES, Alexandre Macedo. Fundamentos de direito tributário. 4. ed. São Paulo: Saraiva, 2009. p. 129.

48 Cabe aqui transcrever parte da crítica de Renato Lopes Becho à classificação da responsabilidade em transferência e substituição: "Anotamos, por oportuno, o que consideramos uma inconsistência na lição de Rubens Gomes de Sousa: a solidariedade, como se observa em seu próprio exemplo (diversos proprietários do mesmo imóvel), não ocorre - necessariamente - 'em virtude de um fato posterior', mas pode ser concomitante ou mesmo anterior ao surgimento do fato imponível (fato gerador), que em seu exemplo é ser proprietário de imóvel. Deixemos mais claro esse importante aspecto, usando alguns exemplos para meIhor compreensão. Imaginemos uma sucessão causa mortis, em que os herdeiros sejam o cônjuge sobrevivente e dois filhos do de cujos. Essas três pessoas serão solidariamente responsáveis pelo IPTU devido após a abertura da sucessão. Se o óbito ocorreu em 2011, podemos até aceitar que tenha havido um fato posterior em relação ao IPTU desse mesmo ano: a obrigação tributária surgiu contra uma pessoa, que posteriormente faleceu e deixou o imóvel como herança para mais de um herdeiro. Todavia, imaginemos que o contribuin- 
presente trabalho, mostra-se mais útil ${ }^{49}$ o enfoque do problema sob a ótica dos efeitos possíveis para as partes envolvidas, como tratado a seguir.

\section{ASPECTOS DA SOLIDARIEDADE}

Para o direito civil ${ }^{50}$ há solidariedade quando na mesma obrigação concorre mais de um credor, ou mais de um devedor, cada um com direito, ou obrigado, à dívida toda. Para o presente estudo, é importante a solidariedade passiva tributária. Ou seja, a solidariedade existente entre os devedores da prestação pecuniária e que funciona como uma garantia de recebimento por parte do credor. O sujeito ativo pode eleger qualquer dos devedores para exigir a totalidade da obrigação sem que haja a necessidade de seguir uma linha hierárquica de cobrança. Isto é, inexiste benefício de ordem ${ }^{51}$. A presença de tal benefício altera a forma da responsabilidade, descaracterizando a solidariedade tributária.

No direito positivo, a solidariedade tributária está prevista no art. 124 do CTN, mas é preciso destacar a existência de disposições diversas nos seus incisos. $\mathrm{O}$ inciso I institui a solidariedade entre aqueles que tenham interesse comum no fato gerador, também denominada solidariedade de fato ${ }^{52}$.

te, logo no início de 2011, tenha quitado o tributo. Quando começar o novo exercício, em 2012, o crédito tributário já vai surgir contra os três contribuintes. Aqui haverá solidariedade e não terá havido, em relação ao IPTU de 2012, nenhum fato posterior que os considere responsáveis tributários (em sentido estrito). Como há mais de um proprietário no ano em que estejamos analisando, o fato gerador já terá nascido para mais de uma pessoa, solidariamente obrigadas. Assim, podemos afirmar que a solidariedade é um efeito da tributação nas hipóteses em que existam mais de um sujeito passivo direto (contribuinte) ou indireto (em uma de suas modalidades). Não se trata de transferência e nem tampouco de sujeição passiva indireta. Pode haver, na solidariedade, sujeição passiva direta." (BECHO, Renato Lopes. As modalidades de sujeição passiva tributária no ordenamento jurídico brasileiro.

Revista Dialética de direito tributário - RDDT, São Paulo, n. 192, p.113-131, set. 2011. p. 126-127).

49 "As classificações não atendem a critérios científicos rígidos e, portanto, variam de acordo com o sistema de referência de quem as faz, já que não há um único método que leve a uma classificação que seja 'verdadeira'. Elas são erigidas segundo critérios utilitaristas eleitos pelos juristas, de modo que sobre elas não pode dizer que sejam verdadeiras ou falsas, válidas ou inválidas. Elas são úteis ou não." (ANDRADE FILHO, Edmar Oliveira. Infrações e sanções tributárias. São Paulo: Dialética, 2003. p. 111).

50 Vide art. 264 do Código Civil.

51 Vide parágrafo único do art. 124 do CTN.

52 NEDER, Marcos Vinicius. Solidariedade de direito e de fato: reflexões acerca de seu conceito. In: Responsabilidade tributária. FERRAGUT, Maria Rita (Coord.). São Paulo: Dialética, 2007. p. 36-42. 
Regina Helena Costa ${ }^{53}$ observa nesse dispositivo o estabelecimento de solidariedade entre contribuintes, vez que tais devedores não são terceiros e realizam o fato gerador. ${ }^{54}$ Seria o caso dos coproprietários de terras rurais que se veem obrigados solidariamente ao pagamento do ITR na condição de contribuintes ${ }^{55}$.

No mesmo sentido, defende Angelo Braga Netto Rodrigues de Melo ${ }^{56}$ para quem o 124, I, do CTN trata do "contribuinte solidário". O autor acredita que o dispositivo faça referência a duas pessoas que realizam o fato presuntivo de riqueza ou, na expressão utilizada no presente trabalho, fato gerador. Ou seja, "a solidariedade vai instalar-se entre os sujeitos que estiverem no mesmo polo da relação se, e somente se, for esse o lado escolhido pela lei para receber o impacto jurídico da exação. ${ }^{57}$ Em outras palavras, cabe citar o hispânico José Juan Ferreiro Lapatza que, ao comentar o equivalente ao CTN espanhol (Lei Geral Tributária), faz as seguintes considerações sobre a solidariedade dos contribuintes:

Como já sabemos, a LGT (art. 35.6) dispõe que a concorrência de várias pessoas na realização do pressuposto de fato de qualquer das obrigações tributárias impostas pela norma tributária determina que ficam solidariamente obrigados perante a Administração ao cumprimento de todas as prestações, salvo que a Lei disponha em contrário. ${ }^{58}$

53 COSTA, Regina Helena. Curso de direito tributário: Constituição e código tributário nacional. São Paulo: Saraiva, 2009. p. 192-193.

54 No mesmo sentido vide LOPES, Mauro Luís Rocha. Direito tributário brasileiro. 2. ed. Niterói, RJ: Impetus, 2010. p. 186.

55 Nesse caso, para Maria Rita Ferragut, "Os devedores solidários são contribuintes no que diz respeito às suas parcelas individualizadas da obrigação divisível (parcela do tributo que corresponde à sua quota de interesse na situação), se existirem, e responsáveis quanto às demais (FERRAGUT, Maria Rita. Responsabilidade tributária e o Código Civil de 2002. São Paulo: Noeses, 2009. p. 69). No mesmo sentido, vide o exposto por Marcos Vinicius Neder (NEDER, Marcos Vinicius. Solidariedade de direito e de fato: reflexões acerca de seu conceito. In: Responsabilidade tributária. FERRAGUT, Maria Rita (coord.). São Paulo: Dialética, 2007. p. 33). No entanto, tais colocações partem da premissa de que a área de cada um dos coproprietários seria identificável, o que é a exceção e não a regra em uma propriedade em comum. Para verificar o montante exato devido por cada um é necessário conhecer detalhadamente a parcela do terreno de cada um, bem como, a utilização dada a cada parte desse imóvel. Não basta saber o percentual que cada um possui da propriedade.

56 MELO, Angelo Braga Netto Rodrigues de. Sujeição tributária passiva. Revista tributária e de finanças públicas. RT, v. 79, mar.-abr./2008. p. 27.

57 CARVALHO, Paulo de Barros. Curso de direito tributário. 14. ed. rev. e atual. São Paulo: Saraiva, 2002. p. 311.

58 LAPATZA, José Juan Ferreiro. Direito tributário: teoria geral do tributo. Barueri, SP: Manole; Espanha, ES: Marcial Pons, 2007. p. 205. 
Apesar do exposto pelos autores estudados, deve-se considerar também a possibilidade do inciso I ser aplicável aos responsáveis. Não como forma de incluir terceiro no polo passivo (instituir a responsabilidade), mas como efeito da relação entre os sujeitos que passaram a fazer parte da relação tributária com outro fundamento legal. Isto é, duas pessoas distintas do contribuinte que, por outra razão prevista em lei, tornaram-se responsáveis e, em virtude do interesse comum que os une, passam a ser, também, solidários entre si. Em outras palavras, quando tenham relação indireta e interesse comum com o critério material ou pessoal que originou o débito do contribuinte.

O próprio CTN contempla exemplo de solidariedade entre os responsáveis. O herdeiro é o terceiro que pode ser chamado a suportar o débito, conforme previsão legal contida no art. 131, II, do CTN, causa de sua inclusão no polo passivo. No entanto, havendo mais de um herdeiro, o dever deles é solidário em relação à dívida. O sujeito ativo pode exigir o crédito tributário de qualquer deles, respeitado o limite do quinhão do legado a que cada um tem direito. Tal previsão de solidariedade não consta no art. 131, mas decorre da comunhão deste com o inciso I do art. 124, ambos do CTN.

Assim, a previsão do inciso I do art. 124 se dá entre contribuintes ou entre responsáveis, nunca na relação contribuinte e responsável ou responsável e contribuinte. A solidariedade debatida até então não pode ser considerada como uma responsabilidade, já que não é ela que possibilita a exigência do crédito de um terceiro que não realizou o fato gerador. Deve ser entendida como efeito da relação entre a multiplicidade de sujeitos passivos que estão em situação semelhante (contribuintes ou responsáveis). ${ }^{59}$

Na solidariedade de que trata o inciso I, não há a inclusão do responsável no polo passivo em decorrência do referido dispositivo. Isso não significa que inexista solidariedade entre contribuinte e responsável, ou responsabilidade tributária solidária, mas apenas que o fundamento legal não está no inciso I. O

59 Em sentido oposto, Fábio Pallaretti Calcini defende que os dois incisos do art. 124 tratam de responsabilidade tributária (CALCINI, Fábio Pallaretti. A responsabilidade tributária e a solidariedade. Algumas considerações ao art. 124 do código tributário nacional. Revista Dialética de direito tributário - RDDT, São Paulo, n. 167, p. 39-54, ago. 2009). 
fato do art. 124 ser aplicável tanto aos contribuintes como aos responsáveis é corroborado por sua posição geográfica no CTN. O dispositivo está dentro do capítulo IV que trata dos "Sujeitos Passivos" e não no que aborda especificamente a "Responsabilidade Tributária".

O inciso II trata especificamente do terceiro que, em virtude de uma previsão legal, pode ser chamado a suportar o crédito tributário, também referida por alguns autores como solidariedade de direito. ${ }^{60} \mathrm{O}$ dispositivo não pode ser compreendido como se a referência fosse ao contribuinte, pois seria redundante uma vez que é sempre indispensável a previsão legal para a instituição deste. Vêse claramente desenhada a figura do responsável tributário solidário, modalidade de sujeição passiva tributária. $O$ inciso comentado é que permite a inclusão de terceiro no polo passivo da relação tributária.

Como abordado, havendo solidariedade, a cobrança pode recair integralmente sobre qualquer dos sujeitos passivos sem a necessidade de qualquer ordem na exigência desta. A previsão permite ao legislador a criação da responsabilidade tributária solidária (sem benefício de ordem) válida apenas entre sujeitos passivos em situações diferentes dentro do polo passivo: entre o contribuinte e o responsável. Nesse caso, ambos figurarão como sujeitos passivos da relação jurídica e estarão sujeitos à cobrança por parte do sujeito ativo em igualdade de condições.

O CTN não traz em seu bojo exemplo de tal hipótese. Apesar de fazer referência no art. 134 à "responsabilidade solidária" entre os administradores de bens de terceiro em relação aos contribuintes, a indicação do benefício de ordem no caput descaracteriza a situação para responsabilidade subsidiária.

A ausência de um exemplo de responsabilidade tributária solidária no CTN não afasta sua existência. Poderia tratar de um efeito da responsabilidade não adotado pelo legislador. No entanto, a Lei Complementar no 123/2006 materializou a solidariedade entre o contribuinte e o responsável ${ }^{61}$ no caso de microempresas e empresas de pequeno porte em relação aos seus sócios, titulares

60 NEDER, Marcos Vinicius. Solidariedade de direito e de fato: reflexões acerca de seu conceito. In: Responsabilidade tributária. FERRAGUT, Maria Rita (Coord.). São Paulo: Dialética, 2007. p. 34-36.

61 Vide $\S \S 3^{\circ}$ e $4^{\circ}$ do art. 78 da Lei Complementar 123, de 14 de dezembro de 2006. 
e administradores. $\mathrm{O} \S 4^{\circ}$ do art. 78 dispunha que administradores ou sócios "são solidariamente responsáveis pelos tributos ou contribuições que não tenham sido pagos ou recolhidos, inclusive multa de mora ou de ofício, conforme o caso, e juros de mora." Apesar da revogação do dispositivo pela Lei Complementar $n^{\circ}$ 128, de 2008, o texto serve para demonstrar a instituição da responsabilidade tributária na modalidade solidária, conforme prevê o art. 124, II, do CTN.

Situação análoga ocorre em relação ao proprietário, ao incorporador, ao dono da obra ou ao condômino de unidade imobiliária que são, juntamente com o construtor, solidariamente responsáveis pelo cumprimento das obrigações para com a Seguridade Social. A Lei $n^{\circ}$ 8.212/91, que trata da organização da Seguridade Social e instituiu o plano de custeio, prevê tal possibilidade no art. $30^{62}$, inciso VI, com redação dada pela Lei n 9.528/97. Além de expressamente indicar a "solidariedade" entre o contribuinte (construtor) e os terceiros mencionados, o legislador fez questão de destacar a inexistência de benefício de ordem entre os devedores para evitar qualquer confusão com outros efeitos da responsabilidade.

No âmbito do Estado de Santa Catarina, o Regulamento do ICMS, Decreto Estadual n².870, de 27 de agosto de 2001, prevê a responsabilidade solidária dos despachantes aduaneiros (terceiros) que tenham promovido o despacho de mercadorias estrangeiras saídas da repartição aduaneira com destino a estabelecimento diverso daquele que a tiver importado ou arrematado (contribuintes).

Percebe-se que a possibilidade aberta pelo CTN, art. 124, II, para a fixação de responsáveis solidários, está sendo implementada na legislação esparsa pouco a pouco.

62 "Art. 30. A arrecadação e o recolhimento das contribuições ou de outras importâncias devidas à Seguridade Social obedecem às seguintes normas: [...]

VI - o proprietário, o incorporador definido na Lei no 4.591, de 16 de dezembro de 1964, o dono da obra ou condômino da unidade imobiliária, qualquer que seja a forma de contratação da construção, reforma ou acréscimo, são solidários com o construtor, e estes com a subempreiteira, pelo cumprimento das obrigações para com a Seguridade Social, ressalvado o seu direito regressivo contra o executor ou contratante da obra e admitida a retenção de importância a este devida para garantia do cumprimento dessas obrigações, não se aplicando, em qualquer hipótese, o benefício de ordem;" 
Em resumo, a solidariedade pode se dar entre contribuintes, entre responsáveis ou entre contribuintes e responsáveis. Caracteriza-se pela possibilidade da (i) exigência integral da dívida, (ii) de qualquer dos sujeitos passivos e (iii) independente de ordem nessa cobrança. No entanto, a responsabilidade tributária solidária tem essas mesmas características e ainda (iv) possibilita a inclusão de terceira pessoa no polo passivo e aplica-se somente na (v) relação do contribuinte e responsável.

A responsabilidade por solidariedade tem o efeito de trazer terceiro para a relação tributária sem, contudo, afastar o contribuinte do polo passivo. O afastamento ou a instituição de uma sequência de devedores que o sujeito ativo deverá seguir para ver seu crédito satisfeito descaracteriza a solidariedade para fins tributários. Nessas situações, são outros os efeitos ou as intensidades ${ }^{63}$ da responsabilidade.

\section{CONSIDERAÇÕES ACERCA DA SUBSIDIARIEDADE}

Cabe relembrar que a responsabilidade tributária tem como fundamento a praticidade e a comodidade na arrecadação, tornando-se para o credor uma garantia extra. Tais características ficam ainda mais marcadas na responsabilidade subsidiária. Nesta haverá a responsabilização do terceiro somente em caso de impossibilidade do pagamento pelo contribuinte, ou seja, pelo devedor original.

Anteriormente tratou-se da possibilidade do Fisco escolher de quem vai exigir a totalidade do crédito tributário. No entanto, caso a lei indique uma sequência de cobrança a ser seguida pelo credor, estará tratando de subsidiariedade tributária e não mais de solidariedade.

O resultado tratado neste item pressupõe que o sujeito ativo tente receber do contribuinte, devedor original, a prestação pecuniária devida. Havendo impossibilidade, estaria permitida a inclusão do terceiro, indicado por lei, exigindose desse o crédito tributário. Segundo Maria Rita Ferragut ${ }^{64}$, o nascimento da 63 FALCÃO, Amílcar. Introdução ao direito tributário. 5. ed. atual. rev. atualizada por Flávio Bauer Novelli. Rio de Janeiro: Forense, 1994. p. 87.

64 FERRAGUT, Maria Rita. Responsabilidade tributária e o código civil de 2002. São Paulo: Noeses, 2009. p. 111. 
relação jurídica se dá com o reconhecimento de que o contribuinte não tem como atender sua obrigação. No momento da ocorrência do fato gerador não haveria que se falar em responsabilidade, estando apenas o contribuinte no polo passivo. O terceiro somente seria incluído na relação jurídica como devedor do Fisco no momento em que restasse comprovada a inviabilidade de recebimento do crédito do contribuinte.

Importante destacar que, apesar da inclusão do terceiro no polo passivo, o contribuinte continua a fazer parte dessa relação tributária como devedor ${ }^{65}$. Ou seja, caso o mesmo retome a condição de suportar a prestação em análise, poderá ser exigido dele o cumprimento do objeto da prestação.

O CTN menciona expressamente a subsidiariedade como uma das consequências da responsabilidade ${ }^{66}$ e se refere a sua sistemática no artigo 134. Apesar de o último indicar que se trata de solidariedade, essa afirmação é objeto de críticas uníssonas ${ }^{67}$, vez que estabelece uma ordem de cobrança. Somente será exigido do responsável caso o contribuinte não possa suportar o ônus da dívida, configurando a responsabilidade subsidiária do primeiro para com o segundo.

Também é possível verificar o efeito da responsabilidade estudado no inciso II do art. 133 do CTN. O adquirente do fundo de comércio será chamado a arcar com o crédito tributário, caso o alienante que prosseguir na exploração ou iniciou outra dentro de seis meses, a contar da data da alienação, não tenha condições de satisfazê-lo. Em outras palavras, inicialmente exige-se do vendedor do fundo de comércio que continua ativo e, na impossibilidade, do comprador. O primeiro será o contribuinte e o segundo o responsável subsidiário.

Em virtude do exposto, resta claro que o limiar distintivo entre a solidariedade e a subsidiariedade está na existência ou não de ordem de cobrança. Estabelecida uma cadeia de devedores a ser seguida, inicialmente o contribuinte e posteriormente

65 VILLELA, Gilberto Etchaluz. Responsabilidade tributária: as obrigações tributárias e responsabilidades: individualizadas, solidárias, subsidiárias individualizadas, subsidiárias solidárias. Porto Alegre: Livraria do Advogado, 2001. p. 61-68.

66 Vide inciso II do art. 133 do CTN.

67 FERRAGUT, Maria Rita. Responsabilidade tributária e o código civil de 2002. São Paulo: Noeses, 2009. p. 111; HARADA, Kiyoshi. Responsabilidade tributária de terceiros. Revista Fórum de Direito Tributário - RFDT, Belo Horizonte, ano 9, n. 50, p.129-140, mar./abr. 2011. 
o responsável, trata-se de subsidiariedade. ${ }^{68}$ Estando o sujeito ativo livre para definir de quem irá exigir a integralidade do crédito, sem qualquer ordem a ser observada, os devedores serão solidários. Em ambos os casos o contribuinte não é afastado da relação jurídica, permanecendo como sujeito passivo mesmo quando o credor passa a exigir a prestação do responsável.

\section{A LIBERAÇÃO DO CONTRIBUINTE}

Diferente das situações anteriores em que a responsabilidade é supletiva ${ }^{69}$, ou seja, em que o responsável funciona com um terceiro garantidor do crédito tributário, na presente situação o devedor original é afastado da relação jurídica e dispensado da prestação, restando no polo passivo apenas o terceiro.

Na própria menção ao responsável, feita pelo CTN, existe a possibilidade de exoneração ${ }^{70}$ do contribuinte da dívida. Essa consequência também é denominada por alguns autores ${ }^{71}$, inspirados no $\mathrm{CTN}^{72}$, como responsabilidade pessoal.

Não se pode compreender que a pessoalidade, como mencionada no art. 135 do CTN, tenha o significado da subsidiariedade, prevista no art. 134 do CTN. Se assim fosse, o Código estaria impondo responsabilização semelhante em situações totalmente opostas $^{73}$, o que por si só é ilógico. ${ }^{74}$ Aliomar Baleeiro defende a possibilidade

68 MACHADO, Hugo de Brito. Curso de direito tributário. São Paulo: Malheiros, 2007. p. 137.

69 Vide art. 128 do CTN.

70 Vide art. 128 do CTN.

71 AMARO, Luciano. Direito tributário brasileiro. 14. ed. São Paulo: Saraiva, 2008. p. 327328; DERZI, Misabel Abreu Machado. In: BALEEIRO, Aliomar. Direito tributário brasileiro. 11. ed. atualizada por Misabel Abreu Machado Derzi. Rio de Janeiro: Forense, 1999. p. 763.

72 Vide arts. 135, 137 e 208 do CTN.

73 No segundo caso haveria atuação regular e no primeiro o responsável agiria contra dispositivo legal, com excesso de poderes ou infringindo contrato social ou estatutos.

74 Esta reflexão não trata do art. 135 do CTN, mas a opinião de Renato Lopes Becho em artigo publicado na Revista Dialética de direito tributário, de fevereiro de 2012, merece ser aqui lembrada, por sua interpretação, nova e ousada: "Conforme exposto no presente estudo, entendemos que a melhor compreensão para o art. 135 é considerá-lo correlato ao art. 158 da Lei no 6.404/1976 (Lei das Sociedades Anônimas). Significa dizer que, quando os responsáveis tributários realizarem atos lícitos contra o interesse do contribuinte e que significarem descumprimento da legislação que liga um e outro (contribuinte e responsável), esses responderão pessoalmente pelos créditos tributários decorrentes de seus atos. Nos termos como positivado pelo legislador, como o responsável terá agido contra os interesses do contribuinte, este será excluído da ação de cobrança (responsabilidade pessoal do terceiro). Essa compreensão - assim como a interpretação dada por juristas de escol (sic) - não encontra ressonância na jurisprudência do egrégio Superior Tribunal de Justiça. Essa 
da alteração do polo passivo com a inclusão do responsável e a exoneração do contribuinte. Para o autor, o art. 135 do CTN trata de situação em que o terceiro passa a ser plenamente responsável pela dívida e não apenas subsidiariamente. Os responsáveis passariam a ser os devedores no lugar dos contribuintes. ${ }^{75}$

Para Maria Lúcia Aguilera76, não há dúvida que a pessoalidade "somente pode configurar responsabilidade exclusiva pelo crédito tributário, devendo ser excluído o contribuinte (devedor originário) do polo passivo". No mesmo sentido, defende Misabel Abreu Machado Derzi para quem há a transferência do "débito, nascido em nome do contribuinte, exclusivamente para o responsável, que o substitui". ${ }^{77}$

Com a liberação do contribuinte, este fica excluído do polo passivo da obrigação, respondendo apenas o terceiro ${ }^{78}$. Pode haver o afastamento por questões fáticas ou legais. A primeira decorre da impossibilidade material de exigência do crédito tributário do contribuinte em virtude do desaparecimento desse sujeito.

A Lei Complementar $n^{\circ} 123 / 2006$, que regula as micros e pequenas empresas, foi citada antes como exemplo de responsabilidade solidária contida no parágrafo $\underline{4^{\circ}}$ do art. 78. Já o art. 90, §5079 indica a existência de "responsabilidade solidária" assertiva reforça a ideia, anteriormente explorada, de que a responsabilidade tributária, como está sendo aplicada, não possui correlação com o que foi decidido pelo legislador quando da elaboração do Código Tributário Nacional." (BECHO, Renato Lopes. Responsabilidade tributária de terceiros: o art. 135 do CTN. Revista Dialética de direito tributário - RDDT, São Paulo, n. 197, p. 127-137, fev. 2012).

75 BALEEIRO, Aliomar. Direito tributário brasileiro. 11. ed. atualizada por Misabel Abreu Machado Derzi. Rio de Janeiro: Forense, 1999. p. 755.

76 AGUILERA, Maria Lúcia. A responsabilidade de terceiros decorrente da prática de ilícitos e o lançamento de ofício: o caso da responsabilidade pessoal dos administradores. In: FERRAGUT, Maria Rita (Coord.) Responsabilidade tributária. São Paulo: Dialética, 2007. p. 126- 142.

77 DERZI, Misabel Abreu Machado. In: BALEEIRO, Aliomar. Direito tributário brasileiro. 11. ed. atualizada por Misabel Abreu Machado Derzi. Rio de Janeiro: Forense, 1999. p. 756.

78 AMARO, Luciano. Direito tributário brasileiro. 14. ed. São Paulo: Saraiva, 2008. p. 327.

79 "Art. 9० O registro dos atos constitutivos, de suas alterações e extinções (baixas), referentes a empresários e pessoas jurídicas em qualquer órgão envolvido no registro empresarial e na abertura da empresa, dos 3 (três) âmbitos de governo, ocorrerá independentemente da regularidade de obrigações tributárias, previdenciárias ou trabalhistas, principais ou acessórias, do empresário, da sociedade, dos sócios, dos administradores ou de empresas de que participem, sem prejuízo das responsabilidades do empresário, dos sócios ou dos administradores por tais obrigações, apuradas antes ou após o ato de extinção. [...]

§ 3을 No caso de existência de obrigações tributárias, previdenciárias ou trabalhistas referido no caput deste artigo, o titular, o sócio ou o administrador da microempresa e da empresa de pequeno porte que se encontre sem movimento há mais de 3 (três) anos poderá solicitar a baixa nos registros dos órgãos públicos federais, estaduais e municipais independentemente do pagamento de débitos tributários, taxas ou multas devidas pelo atraso na 
do sócio ou do administrador no caso de "baixa nos registros dos órgãos públicos" sem o pagamento dos tributos devidos pela empresa. No entanto, tal qual ocorreu em relação à menção feita pelo art. 134 do CTN, o efeito da responsabilidade não seria o referido, mas o de exclusão do Contribuinte. A baixa dos registros encerra a pessoa jurídica e impede o sujeito ativo de efetuar a cobrança do crédito tributário do devedor original. A possibilidade de exigir a dívida do Contribuinte é que caracteriza a responsabilidade tributária solidária ${ }^{80}$ ou subsidiária. Assim, estaria a pessoa jurídica afastada da relação por impossibilidade fática de lá permanecer frente ao seu desaparecimento do mundo jurídico, caracterizando a responsabilidade pessoal do terceiro.

De forma menos genérica, o CTN trata dos casos de extinção de pessoas jurídicas de direito privado quando a exploração da atividade é continuada por qualquer sócio ou seu espólio. ${ }^{81}$ Apesar de não haver indicação expressa sobre qual dos efeitos da responsabilidade seria aplicável ao caso, pode-se afirmar que a impossibilidade de exigência da empresa fornece uma indicação. Ou seja, independente de considerar outras hipóteses de responsabilidade, o contribuinte restaria liberado por questões fáticas.

Situação análoga ocorre na fusão e na incorporação. A empresa incorporada e as fundidas desaparecem, fazendo com que as empresas resultantes respondam sozinhas pelos tributos devidos. ${ }^{82}$

Outro exemplo de liberação do contribuinte por questão material, que acabou sendo positivado, é o falecimento do contribuinte. entrega das respectivas declarações nesses períodos, observado o disposto nos $\S \S 44^{\circ} \mathrm{e}$ 5o deste artigo.

$\S 4$ 4 A baixa referida no $\S 3$ 을 deste artigo não impede que, posteriormente, sejam lançados ou cobrados impostos, contribuições e respectivas penalidades, decorrentes da simples falta de recolhimento ou da prática, comprovada e apurada em processo administrativo ou judicial, de outras irregularidades praticadas pelos empresários, pelas microempresas, pelas empresas de pequeno porte ou por seus sócios ou administradores.

§ 5o A solicitação de baixa na hipótese prevista no § 3 o deste artigo importa responsabilidade solidária dos titulares, dos sócios e dos administradores do período de ocorrência dos respectivos fatos geradores."

80 FALCÃO, Amílcar. Introdução ao direito tributário. 5. ed. atual. rev. atualizada por Flávio Bauer Novelli. Rio de Janeiro: Forense, 1994. p. 88.

81 Vide parágrafo único do art. 132 do CTN.

82 Vide caput do art. 132 do CTN. 
Com a sua morte é inviável a cobrança de qualquer tributo do de cujus. Eventual exigência somente poderá ser direcionada aos terceiros que passarão à condição de responsáveis em virtude do óbito, tanto é que o $\mathrm{CTN}^{83}$ expressamente designou que estes terceiros são "pessoalmente responsáveis".

Como explicitado, além do afastamento do contribuinte por questões fáticas, pode haver a liberação porquestões de direito. O legislador pode, por qualquer razão, decidir afastar aquele que realizou o fato gerador do polo passivo. Com isso, somente seria possível a exigência do terceiro. O CTN também prevê tal possibilidade ao afastar o vendedor de bens do polo passivo, deixando ao adquirente a responsabilidade pessoal pelos débitos ${ }^{84}$. Note-se que não há o desaparecimento do antigo proprietário e que não há qualquer fato que o impeça de responder solidariamente ou subsidiariamente caso fosse essa a escolha legal. No entanto, o texto normativo optou por retirar o contribuinte, que figurou como vendedor, da sujeição passiva tributária, deixando apenas o adquirente como responsável tributário pessoal.

Outra possibilidade de liberação de quem realiza o fato gerador por determinação legal é a substituição tributária. Diferentemente do que ocorre nas situações narradas até então, em que o contribuinte é excluído em virtude de causa posterior à ocorrência do fato gerador, a exigência do contribuinte nem chega a existir. A dívida já é originalmente exigida de pessoa distinta da que realizou o ato presuntivo de riqueza (tributos não vinculados) ou daquela a quem é dirigida a atuação estatal (tributos vinculados). Ivens Gandra da Silva Martins e Marilene Talarico Martins Rodrigues defendem que, sob a ótica da Constituição, sempre que o legislador optar pelo sistema de substituição tributária visando antecipar o recolhimento do tributo "a responsabilidade do substituto tributário é excludente daquela atribuída ao contribuinte substituído". 85

A mesma lição é extraída de decisão do $\operatorname{STF}^{86}$ que analisou a constitucionalidade

83 Vide art. 131, incisos III e II, do CTN.

84 Vide art. 131, inciso I, do CTN.

85 MARTINS, Ivens Gandra da Silva; RODRIGUES, Marilene Talarico Martins. Substituição tributária por antecipação do futuro fato gerador do ICMS - responsabilidade exclusiva do substituto. Revista Dialética de direito tributário - RDDT, São Paulo, n. 170, p. 160168, nov. 2009. p. 163.

86 BRASIL. Supremo Tribunal Federal. Agravo regimental em agravo de instrumento no 207377-SP. Agravante: Levy Martinelli de Lima e Cia Ltda. e Outros. Agravado: Estado de 
do regime de substituição tributária ao aceitar sua sistemática e esclareceu seu efeito sobre aquele que realizou o fato gerador: "retirando-se do revendedor ou varejista, substituído, a responsabilidade tributária." Ou seja, categoricamente afastando o substituído do polo passivo.

Em conclusão, o efeito da responsabilidade tributária pode ser:(i) a solidariedade entre o terceiro e o contribuinte; (ii) a subsidiariedade do responsável quando não seja possível cobrar a dívida do contribuinte; ou. (iii) a liberação do contribuinte e correspondente cobrança do crédito exclusivamente e pessoalmente do terceiro responsável. Tais consequências são importantes para bem compreender o fenômeno da sujeição passiva indireta no que diz respeito à responsabilidade tributária, tal como delineada no Código Tributário Nacional.

\section{REFERÊNCIAS}

AGUILERA, Maria Lúcia. A responsabilidade de terceiros decorrente da prática de ilícitos e o lançamento de ofício: o caso da responsabilidade pessoal dos administradores. In: FERRAGUT, Maria Rita (Coord.) Responsabilidade tributária. São Paulo: Dialética, 2007.

AMARO, Luciano. Direito tributário brasileiro. 14. ed. São Paulo: Saraiva, 2008.

ANDRADE FILHO, Edmar Oliveira. Infrações e sanções tributárias. São Paulo: Dialética, 2003.

ATALIBA, Geraldo. Hipótese de incidência tributária. 4. ed. São Paulo: Malheiros, 2003.

BALEEIRO, Aliomar. Direito tributário brasileiro. 11. ed. atualizada por Misabel Abreu Machado Derzi. Rio de Janeiro: Forense, 1999.

BECHO, Renato Lopes. As modalidades de sujeição passiva tributária no ordenamento jurídico brasileiro. Revista Dialética de direito tributário - RDDT, São Paulo, n. 192, p. 113-131, set. 2011. BECHO, Renato Lopes. Responsabilidade tributária de terceiros: o art. 135 do CTN. Revista Dialética de direito tributário - RDDT, São Paulo, n. 197, p. 127-137, fev. 2012.

BECHO, Renato Lopes. Sujeição passiva e responsabilidade tributária. São Paulo: Dialética, 2000.

São Paulo. Relator: Min. Néri da Silveira. Brasília, 2 de maio de 2000. Diário de Justiça, 9 jun. 2000, p. 23. 
BECKER, Alfredo Augusto. Teoria geral do direito tributário. 2. ed. São Paulo: Saraiva, 1972.

BRASIL. Supremo Tribunal Federal. Agravo regimental em agravo de instrumento n $207377-$ SP. Agravante: Levy Martinelli de Lima e Cia Ltda. e Outros. Agravado: Estado de São Paulo. Relator: Min. Néri da Silveira. Brasília, 2 de maio de 2000. Diário de Justiça, 9 jun. 2000.

CALCINI, Fábio Pallaretti. A responsabilidade tributária ea solidariedade. Algumas considerações ao art. 124 do código tributário nacional. Revista Dialética de direito tributário - RDDT, São Paulo, n. 167, p. 39-54, ago. 2009.

CARNEIRO, Claudio. Curso de direito tributário e financeiro: obra já atualizada com a LC 128/08 e as MPs 449/08 e 451/08. Rio de Janeiro: Lumen Juris, 2009.

CARVALHO, Paulo de Barros. Curso de direito tributário. 14. ed. rev. e atual. São Paulo: Saraiva, 2002.

COSTA, Regina Helena. Curso de direito tributário: Constituição e Código tributário nacional. São Paulo: Saraiva, 2009.

DERZI, Misabel Abreu Machado. In: BALEEIRO, Aliomar. Direito tributário brasileiro. 11. ed. atualizada por Misabel Abreu Machado Derzi. Rio de Janeiro: Forense, 1999.

DIFINI. Luiz Felipe Silveira. Manual de direito tributário. 4. ed. atual. São Paulo: Saraiva, 2008.

FALCÃO, Amílcar. Introdução ao direito tributário. 5. ed. atual. rev. atualizada por Flávio Bauer Novelli. Rio de Janeiro: Forense, 1994.

FERRAGUT, Maria Rita. Responsabilidade tributária e o código civil de 2002. São Paulo: Noeses, 2009.

FERREIRA, Richard Edward Dooli T. A sujeição passiva tributária e a retenção de tributos na fonte. Rio de Janeiro: Lumen Juris, 2008.

GRECO, Marco Aurélio. Responsabilidade de terceiros e crédito tributário: três temas atuais. Revista Fórum de Direito Tributário - RFDT, Belo Horizonte, n. 28, p. 235-249, jul./ago. 2007.

HARADA, Kiyoshi. Responsabilidade tributária de terceiros. Revista Fórum de Direito Tributário - RFDT, Belo Horizonte, ano 9, n. 50, p.129-140, mar./abr. 2011.

LAPATZA, José Juan Ferreiro. Direito tributário: teoria geral do tributo. Barueri, SP: Manole; Espanha, ES: Marcial Pons, 2007.

LOPES, Mauro Luís Rocha. Direito tributário brasileiro. 2. ed. Niterói, RJ: Impetus, 2010. 
MACHADO. Hugo de Brito Machado. A solidariedade na relação tributária e a liberdade do legislador no art. 124, II, do CTN. Revista Dialética de direito tributário - RDDT, São Paulo, n. 195, p. 58-67, dez. 2011.

MARTINS, Ivens Gandra da Silva; RODRIGUES, Marilene Talarico Martins. Substituição tributária por antecipação do futuro fato gerador do ICMS - responsabilidade exclusiva do substituto. Revista Dialética de direito tributário - RDDT, São Paulo, n. 170, p. 160-168, nov. 2009.

MELO, Angelo Braga Netto Rodrigues de. Sujeição tributária passiva. Revista tributária e de finanças públicas. RT, v. 79, mar.-abr./2008.

NEDER, Marcos Vinicius. Solidariedade de direito e de fato: reflexões acerca de seu conceito. In: Responsabilidade tributária. FERRAGUT, Maria Rita (Coord.). São Paulo: Dialética, 2007.

SCHOUERI, Luís Eduardo. Direito tributário. São Paulo: Saraiva, 2011.

SOUZA, Rubens Gomes de. Compêndio de legislação tributária. Rio de Janeiro: Edições Financeiras S.A., 1952. TAVARES, Alexandre Macedo. Fundamentos de direito tributário. 4. ed. São Paulo: Saraiva, 2009.

TIPKE, Klaus; YAMASHITA, Douglas. Justiça fiscal e princípio da capacidade contributiva. São Paulo: Malheiros, 2002.

VILLELA, Gilberto Etchaluz. Responsabilidade tributária: as obrigações tributárias e responsabilidades: individualizadas, solidárias, subsidiárias individualizadas, subsidiárias solidárias. Porto Alegre: Livraria do Advogado, 2001.

Recebido em: jun/2014

Aprovado em: ago/2014 